\title{
Schmorl Node-A Cause of Acute Thoracic Pain: A Case Report and Pathophysiological Mechanism
}

\author{
ODED HERSHKOVICH, MD, MHA, JONATHAN E. J. KOCH, MD, MICHAEL P. GREVITT, FRCS (ORTH) \\ Centre for Spinal Studies and Surgery, Queen's Medical Centre, Nottingham, United Kingdom
}

\begin{abstract}
Purpose: We report a case of a patient with an acute symptomatic Schmorl node (SN) that spontaneously resolved with characteristic imaging findings. The extensive hematological investigations also allow some insight as to the likely pathophysiology of the painful lesion.

Methods: Case report of an acute symptomatic SN.

Results: A fit and athletic 44-year-old female participant in a competitive paddling event developed atypical thoracic pain and was admitted for further investigation. Normal blood results included complete blood cell count, clotting, and D-dimer. Creatine phosphokinase was $63 \mathrm{U} / \mathrm{L}$ (reference $<167 \mathrm{U} / \mathrm{L}$ ) and troponin I levels were not raised. Her only hematological abnormality was an elevated C-reactive protein (CRP) at $60.2 \mathrm{mg} / \mathrm{L}$ (reference $<5 \mathrm{mg} / \mathrm{L}$ ). Magnetic resonance imaging (MRI) scan showed signal hyperintensity involving T7 vertebral body, surrounding an enlarged SN. Patient was given oral nonsteroidal anti-inflammatory drugs, opioid analgesia, and gradually mobilized. After 3 days, the pain had sufficiently subsided and CRP was $17.8 \mathrm{mg} /$ L. Follow-up MRI scan showed some reduction in the T2 hyperintensity and size of the intraosseous herniation. Patient gradually returned to full activities and had no recurrence of symptoms. MRI scan 8 months after the initial scan showed almost complete resolution of the T2 hyperintensity and pan-vertebral marrow edema.

Conclusion: Symptomatic SN should be part of the differential diagnosis of unexplained thoracolumbar pain. Modality of choice for diagnosis would be MRI. Once diagnosed, several treatment options are available with the most likely being spontaneous resolution of symptoms and bone healing within a few months. The conservative approach is recommended when the symptoms can be medically well controlled.
\end{abstract}

Other and Special Categories

Keywords: Schmorl node, thoracic pain

\section{INTRODUCTION}

German pathologist Christian Georg Schmorl $(1861-1932)^{1}$ first described this unique lesion in 1927, seen most frequently in the thoracolumbar spine, an entity that is nowadays referred to as a Schmorl node (SN). These benign pathological entities are also known as intraosseous disc herniations or Geipel hernias, and in contrast to the more common horizontal disc herniations, which penetrate into the spinal canal or to the neural foramina, SNs are a herniation of the nucleus pulposus through the cartilaginous and bony end plate into the body of the adjacent vertebra. ${ }^{2}$

The literature suggests an association between lumbar disc disease, back pain, and the presence of $\mathrm{SN}^{3}$ and although there are a few published models trying to describe and explain the possible development of SN, there is a lack of consensus about its pathogenesis and natural history. ${ }^{4,5}$ Some authors have suggested trauma as a possible cause, creating a weakened disc and vertebral body, thus allowing the SN to develop, whilst others have proposed autoimmunity as a possible factor. ${ }^{6-8}$

This traumatic theory claims that trauma or stress passing through the end plate would lead to the development of an acute $\mathrm{SN}^{9}{ }^{9}$ and several factors allowing this to happen were suggested: either inherent factors such as indentations, ossification gaps, vascular channels, Scheuermann's disease, or acquired factors such as osteoporosis, malignancy, infection, Paget's disease, and hyperparathyroidism. ${ }^{9,10}$ As most SNs accrue after axial loading insult in patients without the preconditions above, the classic case would be in an otherwise healthy nonpredisposed individual. ${ }^{7,11}$

Although there are some rare cases of patients with SNs who have developed symptoms, most cases are asymptomatic and usually an incidental finding; however, there are rare cases of $\mathrm{SN}$ 

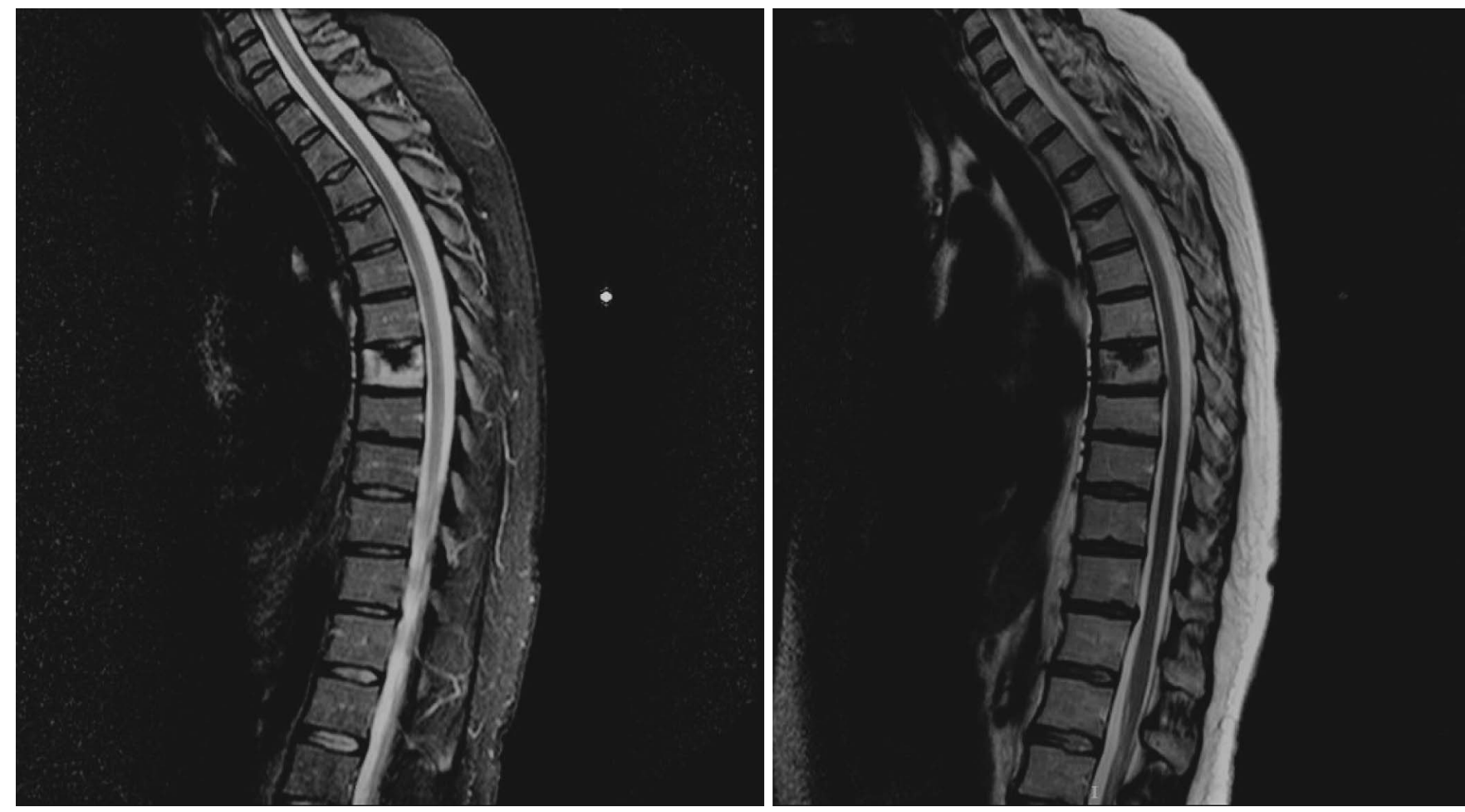

Figure 1. Magnetic resonance imaging (MRI) sagittal T2 STIR—First MRI scan demonstrated high signal intensity on T2 (bone marrow edema) surrounding a large Schmorl node (SN) in T7 vertebral body. A radio-opaque marker on the skin marks the site of the maximum pain. Other smaller SNs are seen in the thoracic spine (left). MRI sagittal T2-First MRI showing the large SN in T7 (right).

described in the literature that present with pain in the spine. ${ }^{10,12-16}$ The diagnosis is usually done by magnetic resonance imaging (MRI), which is the most specific and sensitive modality. ${ }^{15}$

Here, we report the case of a patient with an acute symptomatic SN that spontaneously resolved with characteristic imaging findings. The extensive hematological investigations also allow some insight as to the likely pathophysiology of the painful lesion.

\section{CASE REPORT}

A previously fit and athletic 44-year-old female was a participant in a competitive paddling event. There were no immediate postexercise symptoms, but the next day she had sudden onset of midthoracic pain that was rated as 4/10 intensity. Over the following 3 days, this pain worsened to $10 /$ 10 severity, she was unable to sit for more than 15 minutes, and the pain was not alleviated by lying flat. There was also nocturnal exacerbation.

As the symptoms were not helped by simple overthe-counter analgesia, she attended the local emergency department. Physical examination showed she was apyrexial, and findings were nonspecific apart from reduced spinal movements due to pain; her neurological status was determined to be normal. Localized palpation of her spine did not demonstrate localized tenderness. Her 12-lead electrocardiogram was also found to be normal.

In view of the atypical location of her pain, she was admitted for further investigation. With no recent infection exposure, no recent fever disease, and no history of IV drug use, infection was ruled out. Her full blood count was unremarkable with a normal white cell count, normal clotting profile and D-dimer, and creatine kinase of $63 \mathrm{U} / \mathrm{L}$ (reference $<$ $167 \mathrm{U} / \mathrm{L}$ ). Troponin I levels were not raised, and her only hematological abnormality was an elevated Creactive protein $(\mathrm{CRP})$ at $60.2 \mathrm{mg} / \mathrm{L}$ (reference $<5$ $\mathrm{mg} / \mathrm{L}$ ). Blood cultures were taken and were negative after 48 hours.

The patient's MRI scan showed signal hyperintensity involving the whole $\mathrm{T} 7$ vertebral body, surrounding an enlarged SN, which coincided with the locus of the maximum pain intensity. There were other SNs in the adjacent thoracic vertebrae, but none had altered signal in the bone marrow (Figure 1, left and right). Computed tomography (CT) scan was carried out during the same admission showing some sclerotic bone mirroring the size and extent of the enlarged symptomatic SN, in addition to a small 


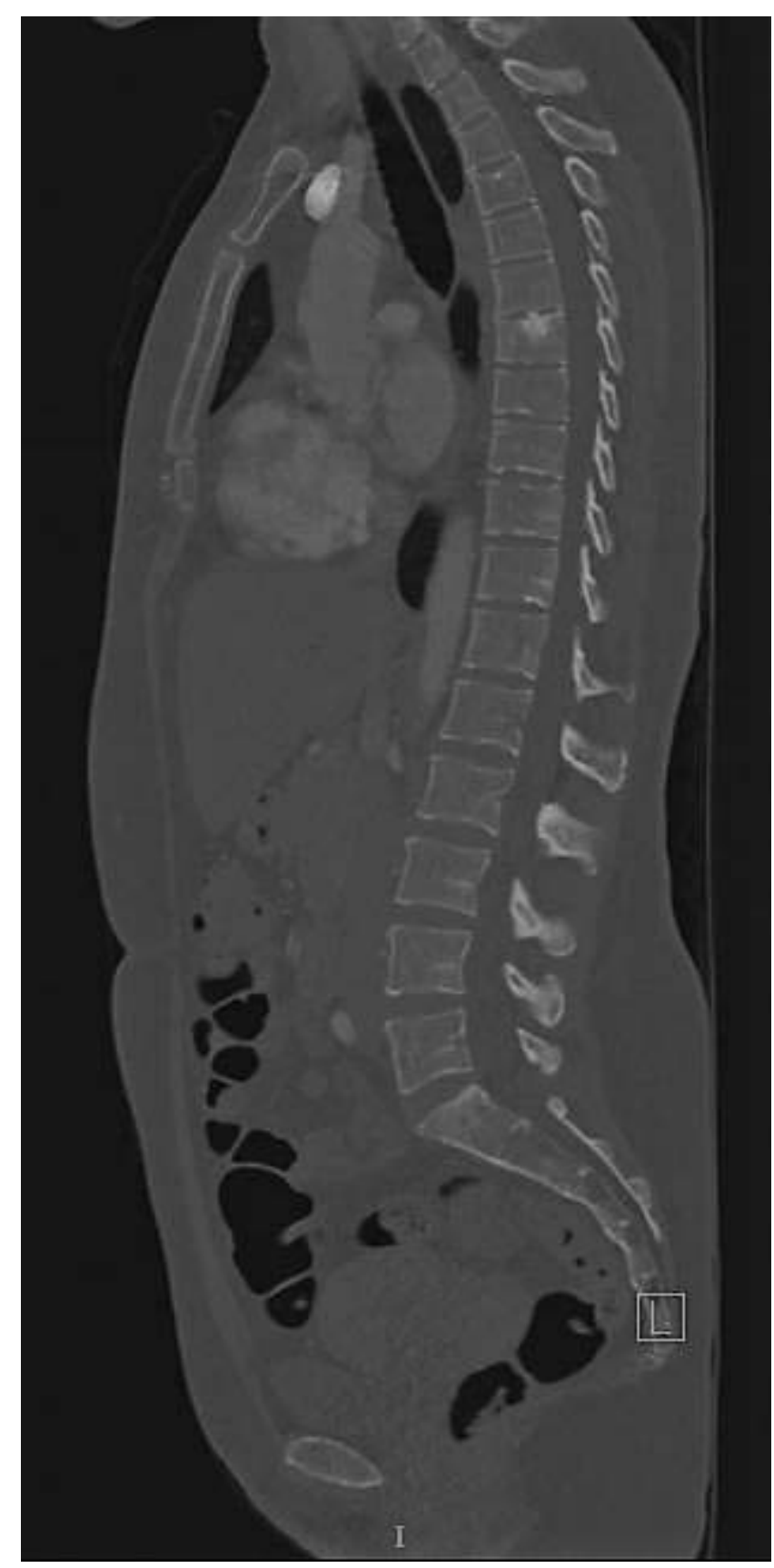

Figure 2. Computed tomography (CT) sagittal-First diagnostic: a combined sclerotic and lytic lesion at the level of the thoracic spine.

area of lysis (Figure 2). Whilst an inpatient, she was given oral nonsteroidal anti-inflammatory medications (Novalgin and ibuprofen), opioid analgesia, and was gradually mobilized. After 3 days, the pain had subsided sufficiently for discharge, at which point her CRP was $17.8 \mathrm{mg} / \mathrm{L}$, still elevated from baseline but greatly reduced from time of admission.

She was reviewed by a spinal surgeon 11 weeks after the initial onset of symptoms, by which time she was largely asymptomatic. A follow-up MRI

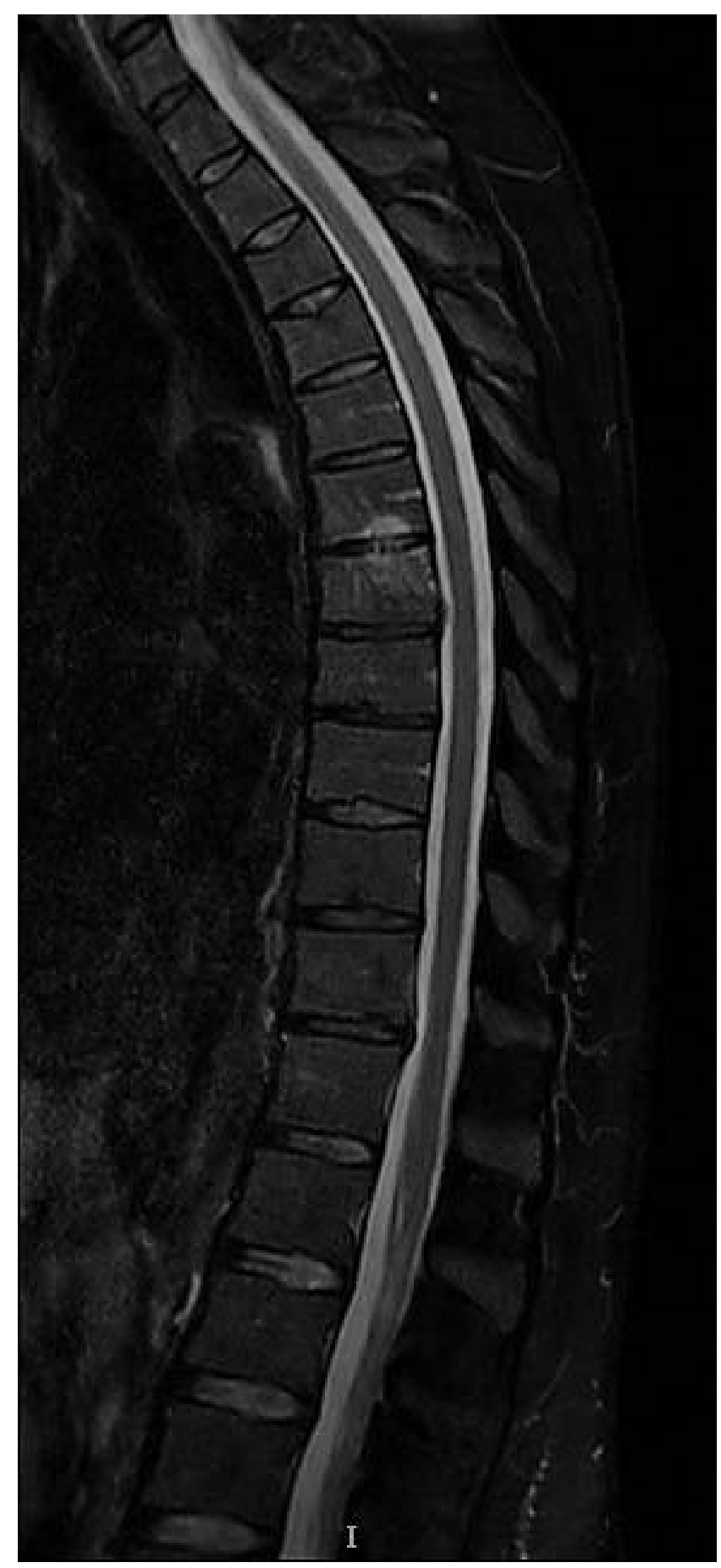

Figure 3. Magnetic resonance imaging (MRI) sagittal T2 at 3-month followup-Partial resolution of the Schmorl node (SN) hyperintensity at T7; some novel inferior end plate edema at T6.

scan showed some reduction in the T2 hyperintensity and size of the intraosseous herniation. There was also some novel T6 inferior end plate edema that was not associated with any bone infraction (Figure 3).

The patient returned to full activities, including competitive tennis, and had no recurrence of 


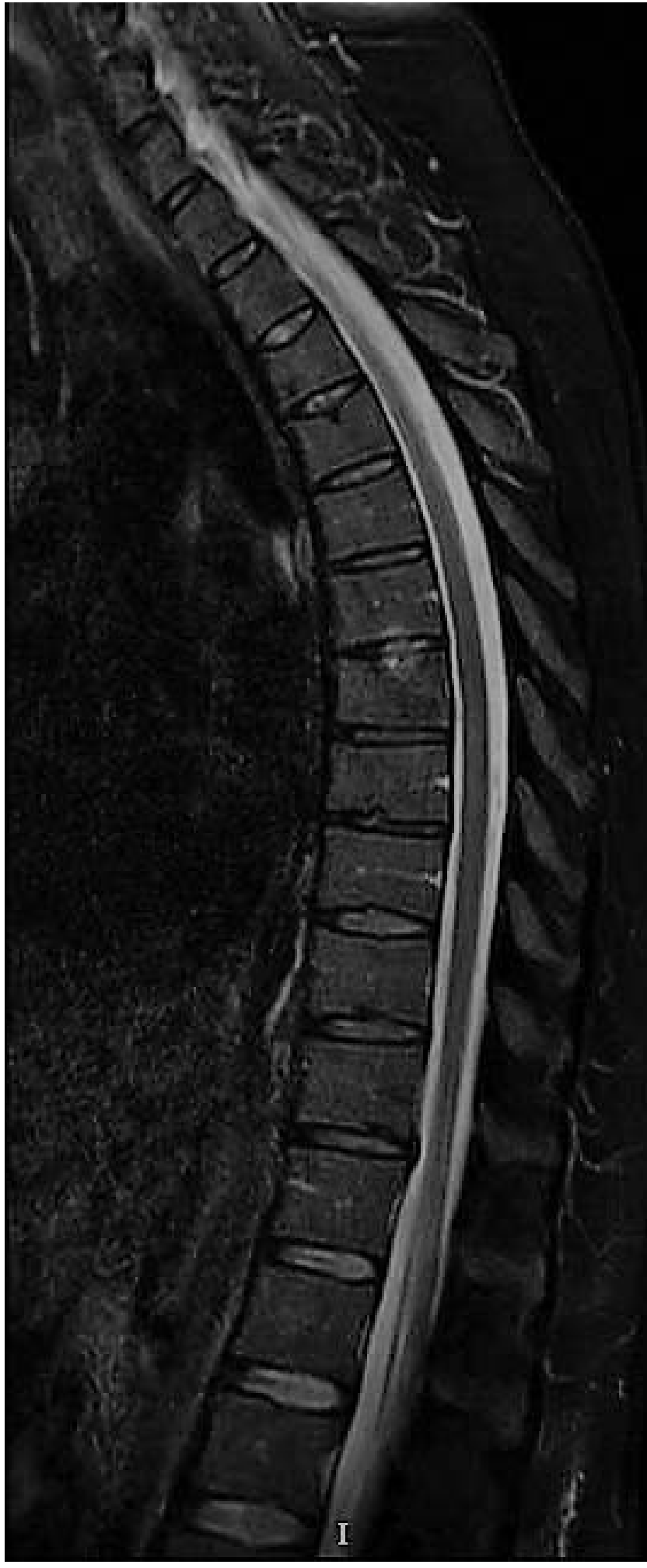

Figure 4. Magnetic resonance imaging (MRI) sagittal T2 at 8-month followup-Complete resolution of the initial Schmorl node (SN) changes.

symptoms. A final MRI scan 8 months after the initial procedure showed an almost complete resolution of the T2 hyperintensity and panvertebral marrow edema, and that there was also significant healing of the bone defect created by the initial intraosseous disc herniation (Figure 4).

\section{DISCUSSION}

Back pain is a very common complaint, and in many cases people are initially treated empirically for the pain and the diagnosis of the specific cause is found later. The differential diagnosis is very wide, including infections, inflammatory, neoplastic, autoimmune, musculoskeletal, and psychosocial etiologies, but for most back pain cases a diagnosis will remain nonspecific. ${ }^{17,18}$ Thoracic back pain is less common, and in our case a diagnosis of acute SN causing an acute episode of axial pain was diagnosed. This was after a thorough evaluation excluding all other causes of back pain based on the patient's clinical history, physical examination, and appropriate imaging modalities.

Overall, SNs are a very common finding and mostly asymptomatic. ${ }^{11}$ The prevalence of SNs vary in the literature but can be as high as $75 \%$ of the population, with this prevalence increasing alongside age and with a peak at around the fourth decade of life. ${ }^{4,11,19,20} \mathrm{SNs}$ are usually located at the thoracolumbar spine although are also diagnosed in other parts of the spine, ${ }^{21}$ with the upper lumbar spine also being considered as susceptible to the development of these lesions. ${ }^{22}$ Other publications found that T7-L1 were the most frequently involved levels. ${ }^{11,23,24}$

Clinically, most SNs will be asymptomatic and most would be an incidental finding on imaging and, when symptomatic and causing back pain, the conformation of diagnosis would be based on imaging. Past studies have shown a high prevalence of asymptomatic SNs, but when they are symptomatic they can be debilitating, causing significant pain, with a greatly negative influence on the patient's well-being and function. ${ }^{11,24}$

Plain radiography can identify an $\mathrm{SN}$ in some of the cases, but not always, ${ }^{25}$ and the MRI is considered to be the most accurate modality, ${ }^{15}$ able to distinguish an active $\mathrm{SN}$ from nonactive, something that correlates with symptoms. Differentiation between symptomatic and asymptomatic SNs is by visualizing edema in T2-weighted images with simultaneous low signal intensity on T1weighted images. ${ }^{11,26}$ Although SNs can be seen on plain radiography, $\mathrm{CT}$, and even bone scan, ${ }^{27}$ MRI is the preferred modality for diagnosis for clinically active SNs due to its superior ability to 
detect bone marrow edema and neovascularization changes. ${ }^{28}$ Although in many cases $\mathrm{SNs}$ are an incidental finding with no associated symptoms, it was found that, when comparing the MRI finding of symptomatic patients with low back pain to those without symptoms, the prevalence of SNs are higher in the symptomatic group. ${ }^{25}$ Furthermore, others have found an association between the signal intensity of the marrow around the $\mathrm{SNs}$ and symptoms, specifically that a low signal $\mathrm{T} 1$ and a hyperintense $\mathrm{T} 2$ can be identified in symptomatic patients similar to this case. ${ }^{15,28,29}$ The extent of the involvement can vary: as in this report, the signal can involve the entire vertebra above, below, or even both. ${ }^{15,30}$

The pathophysiology of symptomatic SNs remains unclear. Saal ${ }^{31}$ has demonstrated that the degenerating disc has significant inflammatory mediators (such as phospholipase A2, prostaglandins, and substance P), and these data suggest that once cytokines are released from the intradiscal milieu they can cause perineural inflammation and radiculopathy. SNs are believed to herniate through a defect in the end plate arising from the notochordal remnant, and, as such, this area represents an area of biomechanical vulnerability ${ }^{2}$; normal load on a healthy disc is distributed evenly, but peak loading may cause pain. ${ }^{32}$ Cytokines are present and contribute to the degenerative cascade in intervertebral discs, ${ }^{33}$ thus, end plate defects may allow disc material to herniate into the vertebral marrow and excite an intense inflammatory reaction ${ }^{26}$; cytokines also mediate bone resorption. ${ }^{34}$ Our case supports the proposed mechanism: acute disc material herniation caused a localized inflammatory reaction, which was sufficient to generate a rise in CRP, and the initial imaging demonstrated the pan-vertebral hyperintensity on short TI inversion recovery MRI. This inflammatory etiology would also explain the rapid symptomatic response in our case to nonsteroidal anti-inflammatory drugs (NSAIDs) and fall in CRP level, ${ }^{12}$ a situation that is analogous to the response of osteoid osteoma to NSAIDs as the pain from osteoid osteoma is also mediated via an inflammatory response and characterized by osteoblastic proliferation; the latter may also explain the rapid bone healing seen in follow-up MRI scans in this report. The chemokine transforming growth factor $\beta$ (TGF $\beta)$ has a major role in signaling in osteoblast differentiation and bone healing ${ }^{35}$; thus, we speculate that the same cytokine-mediated inflammation that causes pain in $\mathrm{SN}$, via a TGF $\beta$ mediated pathway, leads to osteoblastic proliferation and therefore to bone healing. The increased prevalence of mesenchymal cells in the bone marrow ensures a large supply of osteoprogenitor cells that can differentiate and form bone. ${ }^{36}$

Once a diagnosis is made, the treatment for a symptomatic SN is conservative in most cases, aiming for pain control and waiting for the symptoms to improve. The literature describes a wide range of treatment options, including segmental fusion surgery, percutaneous vertebroplasty, tumor necrosis factor- $\alpha$ inhibition, or ramus communicans nerve block, ${ }^{11,26}$ although the latter is not commonly used due to symptoms usually resolving over time.

\section{CONCLUSION}

Symptomatic SN should be part of the differential diagnosis of thoracolumbar unexplained pain, and the modality of choice for diagnosis would be MRI. Once an inflammatory SN is diagnosed, several treatment options are available. However, the most likely outcome is spontaneous resolution of symptoms and bone healing within a few months. As demonstrated in this case, the conservative approach is recommended when the symptoms can be medically well controlled.

\section{REFERENCES}

1. Schmorl G. Über die an den Wirbelbandscheiben vorkommenden Ausdehnungs- und Zerreißungs-vorgänge und die dadurch an ihnen und der Wirbelspongiosa hervorgerufenen Veränderungen. Verh Dtsch Path Ges. 1927;22:250-262.

2. Schmorl G. The Human Spine in Health and Disease. Junghanns H, 5th German ed. Besemann, EF, trans-ed. 2nd American ed. New York: Grune and Stratton; 1971:85.

3. Williams F, Manek NJ, Sambrook PN, Spector TD, Macgregor AJ. Schmorl's nodes: common, highly heritable, and related to lumbar disc disease. Arthritis Care Res. 2007;57(5):855-860.

4. Hilton R, Ball J, Benn R. Vertebral end-plate lesions (Schmorl's nodes) in the dorsolumbar spine. Ann Rheum Dis. 1976;35(2):127.

5. Coventry MB, Ghormley RK, Kernohan JW. The intervertebral disc: its microscopic anatomy and pathology. Part I. Anatomy, development, and physiology. JBJS. 1945;27(1):105-112.

6. Keyes DC, Compere EL. The normal and pathological physiology of the nucleus pulposus of the intervertebral disc: an anatomical, clinical, and experimental study. JBJS. 1932;14(4):897-938.

7. Fahey V, Opeskin K, Silberstein M, Anderson R, Briggs C. The pathogenesis of Schmorl's nodes in relation to acute 
trauma: an autopsy study. Spine (Phila Pa 1976). 1998;23(21):2272-2275.

8. Zhang N, Li FC, Huang YJ, Teng C, Chen WS. Possible key role of immune system in Schmorl's nodes. Med Hypotheses. 2010;74(3):552-554.

9. Wu HT, Morrison WB, Schweitzer ME. Edematous Schmorl's nodes on thoracolumbar MR imaging: characteristic patterns and changes over time. Skeletal Radiol. 2006;35(4):212-219.

10. Jang JS, Kwon HK, Lee JJ, Hwang SM, Lim SY. Rami communicans nerve block for the treatment of symptomatic Schmorl's nodes-a case report. Korean J Pain. 2010;23(4):262265.

11. Kyere KA, Than KD, Wang AC, et al. Schmorl's nodes. Eur Spine J. 2012;21(11):2115-2121.

12. Grivé E, Rovira A, Capellades J, Rivas A, Pedraza S. Radiologic findings in two cases of acute Schmörl's nodes. Am J Neuroradiol. 1999;20(9):1717-1721.

13. Smith DM. Acute back pain associated with a calcified Schmorl's node: a case report. Clin Orthop Relat Res. 1976(117):193-196.

14. Lipson SJ, Fox DA, Sosman JL. Symptomatic intravertebral disc herniation (Schmorl's node) in the cervical spine. Ann Rheum Dis. 1985;44(12):857.

15. Takahashi K, Miyazaki T, Ohnari H, Takino T, Tomita K. Schmorl's nodes and low-back pain. Analysis of magnetic resonance imaging findings in symptomatic and asymptomatic individuals. Eur Spine J. 1994;4(1):56-59.

16. Abu-Ghanem S, Ohana N, Abu-Ghanem Y, Kittani M, Shelef I. Acute Schmorl node in dorsal spine: an unusual cause of a sudden onset of severe back pain in a young female. Asian Spine J. 2013;7(2):131-135.

17. Hoy D, Bain C, Williams G, et al. A systematic review of the global prevalence of low back pain. Arthritis Rheum. 2012;64(6):2028-2037.

18. Hooten WM, Cohen SP. Evaluation and treatment of low back pain: a clinically focused review for primary care specialists. Mayo Clin Proc. 2015;90(12):1699-1718.

19. Sonne-Holm S, Jacobsen S, Rovsing H, Monrad H. The epidemiology of Schmorl's nodes and their correlation to radiographic degeneration in 4,151 subjects. Eur Spine J. 2013;22(8):1907-1912.

20. Jagannathan D, Indiran V, Hithaya F. Prevalence and clinical relevance of Schmorl's nodes on magnetic resonance imaging in a tertiary hospital in Southern India. J Clin Diagn Res. 2016;10(5):TC06-TC09.

21. Mohty KM, Mandair D, Munroe B, Baldemor D. A case of persistent low back pain in a young female caused by a trauma-induced Schmorl's node in the lumbar spine five vertebra. Cureus. 2017;9(7):e1502.

22. Mok FP, Samartzis D, Karppinen J, Luk KD, Fong DY, Cheung KM. ISSLS prize winner: prevalence, determinants, and association of Schmorl nodes of the lumbar spine with disc degeneration: a population-based study of 2449 individuals. Spine (Phila Pa 1976). 2010;35(21):1944-1952.

23. Dar G, Masharawi Y, Peleg S, et al. Schmorl's nodes distribution in the human spine and its possible etiology. Eur Spine J. 2010;19(4):670-675.
24. Pfirrmann CW, Resnick D. Schmorl nodes of the thoracic and lumbar spine: radiographic-pathologic study of prevalence, characterization, and correlation with degenerative changes of 1,650 spinal levels in 100 cadavers. Radiology. 2001;219(2):368-374.

25. Hamanishi C, Kawabata T, Yosii T, Tanaka S. Schmorl's nodes on magnetic resonance imaging. Their incidence and clinical relevance. Spine (Phila Pa 1976). 1994;19(4):450-453.

26. Mattei TA, Rehman AA. Schmorl's nodes: current pathophysiological, diagnostic, and therapeutic paradigms. Neurosurg Rev. 2014;37(1):39-46.

27. Crawford BA. Bone scintigraphy in acute intraosseous disc herniation. Clin Nuclear Med. 2007;32(10):790-792.

28. Stäbler A, Bellan M, Weiss M, Gärtner C, Brossmann J, Reiser MF. MR imaging of enhancing intraosseous disk herniation (Schmorl's nodes). AJR Am J Roentgenol. 1997;168(4):933-938.

29. Walters G, Coumas JM, Akins CM, Ragland RL. Magnetic resonance imaging of acute symptomatic Schmorl's node formation. Pediatr Emerg Care. 1991;7(5):294-296.

30. Seymour R, Williams LA, Rees JI, Lyons K, Lloyd DC. Magnetic resonance imaging of acute intraosseous disc herniation. Clin Radiol. 1998;53(5):363-368.

31. Saal JS. The role of inflammation in lumbar pain. Spine (Phila Pa 1976). 1995;20(16):1821-1827.

32. Mulholland RC. The myth of lumbar instability: the importance of abnormal loading as a cause of low back pain. Eur Spine J. 2008;17(5):619-625.

33. Risbud MV, Shapiro IM. Role of cytokines in intervertebral disc degeneration: pain and disc content. Nat Rev Rheumatol. 2014;10(1):44-56.

34. Mundy GR. Role of cytokines in bone resorption. J Cell Biochem. 1993;53(4):296-300.

35. Poniatowski ŁA, Wojdasiewicz P, Gasik R, Szukiewicz D. Transforming growth factor Beta family: insight into the role of growth factors in regulation of fracture healing biology and potential clinical applications. Mediators Inflamm. 2015;2015:137823.

36. Garg P, Mazur MM, Buck AC, Wandtke ME, Liu J, Ebraheim NA. Prospective review of mesenchymal stem cells differentiation into osteoblasts. Orthop Surg. 2017;9(1):13-19.

Corresponding Author: Oded Hershkovich, Centre for Spinal Studies and Surgery, Queen's Medical Centre, Nottingham NG7 2UH, United Kingdom. Phone: +44 0115924 9924; Email: oded. hershkovich@gmail.com.

Published 30 June 2020

This manuscript is generously published free of charge by ISASS, the International Society for the Advancement of Spine Surgery. Copyright (C) 2020 ISASS. To see more or order reprints or permissions, see http://ijssurgery.com. 